\section{Clinico-anatomical Analysis of the Oculomotor Fasciculus}

Key words: Hess chart, inferior oblique palsy, midbrain infarction, Parks' three-step test, vertical diplopia

\section{(Intern Med 50: 2077, 2011)}

(DOI: 10.2169/internalmedicine.50.5801)

The Authors Reply We wish to thank Dr. Tsuda and colleagues for their interest in our paper (1). In their commentary, Tsuda et al speculated as to whether or not the patient described in our report had palsy of the left medial rectus muscle. In our report, we describe a patient who presented with vertical diplopia. Although horizontal diplopia was not clinically detected, a subclinical palsy of the left medial rectus muscle may potentially exist. As mentioned by Tsuda and colleagues, there is evidence to suggest that the medial rectus muscle fibers are localized between the fibers for the inferior oblique and levator palpebrae muscles (2-4). Because the inferior oblique and levator palpebrae muscle fibers were impaired in our patient, we agree with their suggestion.

Additionally, the possibility of sphincter muscle impairment was also raised. Tsuda et al previously reported findings from a patient with paramedian midbrain infarction presenting with partial oculomotor nerve palsy coupled with restricted elevation and adduction capabilities, and mydriasis (5). The location of the infarct in their patient was similar to our patient. However, in our patient both pupils were $4 \mathrm{~mm}$ with normal direct and consensual light reflexes.
Based on the findings presented previously, the fibers for the pupil lie medial to the midbrain, which is in contrast to fibers for the levator palpebrae, medial rectus and inferior oblique muscles (2-4). Hence, the sphincter muscle was not impaired in our patient.

In this report, it was the fibers controlling the inferior oblique muscle that caused vertical diplopia. While the fibers for the pupil were preserved, there is the potential that the fibers controlling the medial rectus muscle were also slightly impaired.

The authors state that they have no Conflict of Interest (COI).

Naoki Saji ${ }^{1,2}$, Minoru Tanigawa ${ }^{3}$, Yasushi Kita ${ }^{1}$ and Koichi Yokono ${ }^{2}$

\section{References}

1. Saji N, Tanigawa M, Kita Y, Yokono K. Vertical diplopia due to midbrain infarction. Intern Med 50: 531-532, 2011.

2. Castro O, Johnson LN, Mamourian AC. Isolated inferior oblique paresis from brain-stem infarction. Perspective on oculomotor fascicular organization in the ventral midbrain tegmentum. Arch Neurol 47: 235-237, 1990.

3. Ksiazek SM, Slamovits TL, Rosen CE, Burde RM, Parisi F. Fascicular arrangement in partial oculomotor paresis. Am J Ophthalmol 118: 97-103, 1994.

4. Schwartz TH, Lycette CA, Yoon SS, Kargman DE. Clinicoradiographic evidence for oculomotor fascicular anatomy. J Neurol Neurosurg Psychiatry 59: 338, 1995.

5. Tsuda H, Ishikawa H, Majima T, Sawada U, Mizutani T. Isolated oculomotor nerve palsy in Churg-Strauss syndrome. Intern Med 44: 638-640, 2005.

\footnotetext{
${ }^{1}$ Department of Neurology, Hyogo Brain and Heart Center at Himeji, Japan, ${ }^{2}$ Internal and Geriatric Medicine, Kobe University Graduate School of Medicine, Japan and ${ }^{3}$ Department of Ophthalmology, Nippon Steel Hirohata Hospital, Japan Received for publication May 12, 2011; Accepted for publication May 30, 2011

Correspondence to Dr. Naoki Saji, sajink@nifty.com

(C) 2011 The Japanese Society of Internal Medicine

Journal Website: http://www.naika.or.jp/imindex.html
} 